\title{
Heart rate as a minimal cue for the occurrence of conditioned vicarious autonomic responses ${ }^{1}$
}

\author{
DIANE F. KRAVETZ, The University of \\ Michigan, Ann Arbor, Mich. 48104
}

Three groups of $S s$ participated in a vicarious conditioning experiment. Ss heard the heart beats of a model who ostensibly was either being shocked following a tone or who was exercising. Among those hearing a model being shocked, half heard a change in heart rate after each shock; for the remaining half, no change in heart rate occurred. Heart rate and GSR of the actual Ss were collected as measures of vicarious conditioning. GSR data showed no significant effects. However, heart-rate changes showed that conditioning occurred in the experimental condition and in one of the control conditions. The results of this study suggest that heart rate of a model is a salient cue for the occurrence of vicarious classical conditioning.

Research concerned with vicarious emotional instigation suggests (1) that emotional responses of a model elicit emotional responses in Os (Lazarus et al, 1962), and (2) that an O's vicariously aroused emotional responses may become associated with formerly neutral stimuli (Berger, 1962; Bandura \& Rosenthal, 1966; Craig \& Lowery, 1969). In vicarious instigation, the unconditioned emotional response of the model serves as the unconditioned stimulus for the $O$ 's own emotional response. The meaning of the given unconditioned emotional response is inferred by the $O$ from the context and from the related behaviors of the model.

In research on vicarious emotional instigation, it has usually been the overt behavior of the model that provided the $O$ with principal information concerning the internal state of the former. The question can be raised whether providing the $O$ with more direct access to the model's internal state, associated with a given emotion, would be more or less efficient in producing similar emotional reactions in the O. Schachter \& Singer (1962) and Valins (1966) conclude from their studies that internal events can be important sources of information for an individual when he interprets his own feelings and behavior. These studies suggest that cognitive interpretation of one's own physiological responses may be the basis for evaluation of these responses in others. In light of the above research, the present experiment sought to determine if
No $\Delta$ HR-Sh condition, the tape also included a burst of white noise presented to Os as the sound of a shock machine (UCS). Five consecutive adaptation trials were followed by 12 conditioning trials, and interspersed among these 12 were 14 test trials, their order determined randomly.

The tape for the experimental condition ( $\Delta$ HR-Sh) contained all cues of a heart-rate conditioning experiment. During adaptation and test trials, a tone was presented and followed by continuation of the heart rate at $72 \mathrm{bpm}$. However, for conditioning trials, the tone was followed by a 6 -sec presentation of the sound of a shock machine, after which the heart rate was noticeably increased for $10 \mathrm{sec}$.

The timing of the two control tapes was exactly the same as that of the experimental condition tape; only the number of cues available to the $O$ was varied. To control for the UCS ( $\triangle$ HR-NoSh), the tape consisted only of an increased heart rate; the sound of the shock machine was omitted. As noted above, the Os were told that they were hearing the heart rate of a $S$ doing exercises after presentation of a tone. To control for the UCR (No $\triangle$ HR-Sh), the sound of the shock machine was never followed by a noticeable increase in heart rate. Os were told that they were listening to the heart rate of a $S$ who was in a heart-rate conditioning experiment, the same instructions given to the experimental group. Os' own heart rates and GSR were collected as measures.

All Os were briefly interviewed after the experiment. Any $O$ who had not accepted the cover story or did not believe that he had been listening to the heart rate of a $S$ was excluded from the sample.

\section{RESULTS}

Heart rate was measured for $15 \mathrm{sec}$ preceding and for $15 \mathrm{sec}$ following CS onset. The data consisted of the differences between the Os' mean pre-CS heart rate and the mean post-CS heart rate, calculated separately for adaptation, conditioning, and test trials. GSRs were defined as decreases in skin resistance of $1,000 \mathrm{ohms}$ or greater. This movement had to occur within $4 \mathrm{sec}$ following the termination of the CS.

A two-way analysis of variance for changes in skin resistance failed to support the hypothesis that GSR was a function of the differences between conditions $(\mathrm{F}=0.952, \mathrm{df}=2 / 15$, n.s. However, a similar analysis of heart-rate changes showed significant differences between conditions $(F=21.61, \mathrm{df}=2 / 15, \mathrm{p}<.05)$ and between trials $(F=11.45, \mathrm{df}=2 / 30$, $\mathrm{p}<.05$ ). Also significant was the interaction between condition and trials 
Table 1

Mean Changes in Heart Rate During Adaptation, Conditioning, Test Trials*

\begin{tabular}{lcccrc}
\hline Condition & Adaptation & Conditioning & Test & l. (df $=2 / 30)$ & $\mathrm{p}$ \\
\hline$\Delta \mathrm{HR}-\mathrm{Sh}$ & $1.466^{\mathrm{a}}$ & $2.097^{\mathrm{b}}$ & $2.428_{\mathrm{b}}$ & 7.20 & $<.05$ \\
$\Delta \mathrm{HR}-\mathrm{NoSh}$ & $0.733_{\mathrm{a}}$ & $1.514_{\mathrm{b}}$ & $1.868_{\mathrm{b}}$ & 10.17 & $<.05$ \\
No $\Delta \mathrm{HR}-\mathrm{Sh}$ & $1.533_{\mathrm{a}}$ & $1.375_{\mathrm{a}}$ & $1.559_{\mathrm{a}}$ & .30 & NS \\
\hline
\end{tabular}

* Means within cach row haling subscripts in common are not significantly different from each other.

$(\mathrm{F}=3.105, \mathrm{df}=4 / 30, \mathrm{p}<.05)$. Table 1 shows mean heart-rate changes observed during adaptation, conditioning, and test trials in the three conditions. Simple effects tests show that there were significant differences between trials in the experimental condition ( $\Delta$ HR-Sh) and in one of the control conditions ( $\triangle$ HR-NoSh). In both of these conditions, Newman-Keuls tests reveal that the conditioning trials did not differ from the test trials. while both were significantly different from adaptation trials. These results can be taken to indicate that conditioning was accomplished for the experimental Os ( $\Delta \mathrm{HR}-\mathrm{Sh})$ and for Os who heard changes in the heart rate of an individual ostensibly engaged in exercises ( $\Delta$ HR-NoSh). No differences between adaptation, conditioning, and test trials were found for Os who heard a person being shocked but whose heart rate remained constant (NoدHR-Sh).

\section{DISCUSSION}

In general, the results suggest that changes in another person's heart rate can be salient cues of his emotional reaction and, as such, be a basis for the occurrence of vicarious emotional instigation and the conditioning of the O's own heart rate. However, on the basis of the present results, it appears that heart rate was not sufficient to produce vicarious conditioning of the galvanic skin response.

No systematic attempt was made to analyze cognitive processes of Os. However, one interesting observation can be made from postexperimental interviews. Os in conditions involving shock often stated that they quickly forgot about the "S" and were not concerned about him. However, those in Condition $\triangle$ HR-NoSh reported that they actively thought about the " $S$ " throughout the experiment, picturing and imagining what exercises he was doing.

Since no shock is mentioned in Condition $\triangle \mathrm{HR}-\mathrm{NoSh}$, it is notable that Os in this condition were successfully conditioned, while those in Condition No $\Delta$ HR-Sh were not. On early trials, Os in Condition No $\Delta$ HR-Sh showed greater responsiveness to the $\mathrm{CS}$ than $\mathrm{Os}$ in Condition $\triangle$ HR-NoSh: however, these early responses emitted on adaptation trials were not significantly different from their responses to the CS following training. On the other hand. during adaptation trials, Os in Condition $\triangle \mathrm{HR}-\mathrm{NoSh}$ showed little reaction to the $C S$, but after presentation of the CS-UCS pairings, their responses became as strong as those in Condition $\Delta$ HR-Sh.

It appears that a form of socially mediated heart-rate conditioning was achieved in the present experiment. The manipulation that established the situation as either aversive or nonaversive had a significant effect on both physiological and cognitive processes. It affected the sensitivity of Os during adaptation trials and their cognitive work throughout the experiment. It is also evident that of the two cues presented, heart rate and shock, heart rate was the more important and had more pronounced effects. When heart rate was consistent with the information presented by the $\mathrm{F}$, heart-rate conditioning occurred. However, discrepancy between

\section{P. S. DELIN and J. H. BUXTON, University of Adelaide, Adelaide, South Australia 5001}

A list of 10 noun paired associates was learned by three groups of $S s$ under conditions $R T T, R T R$, and $R T$. An additional test trial was given a week later. The results suggest that once a correct response can be produced, further test trials facilitate future recall as much as do further reinforced trials.

As early as $1926, \mathrm{Pal}$ demonstrated that the learning of verbal material is facilitated by the interpolation of test $(\mathrm{T})$ trials in a series of reinforced (R) trials. More recently, Estes (1960) investigated the effect of interpolated $\mathbf{T}$ trials and concluded that they improved retention by providing an opportunity for responses learned on prior $\mathrm{R}$ trials to become conditioned to more stimuli. Izawa (1969), after a series of studies comparing the effects of $T$ and $R$ trials in paired-associate learning, concluded that interpolated heart-rate cues and instructional set apparently prevented conditioning.

\section{REIERENCES}

BANDL:RA, A., \& ROSENTHAL, T. L. Vicarious classical conditioning as a function of arousal level. Journal of Personality \& Social Psychology, 1966, 3, 54-62.

BERGER, S. M. Conditioning through vicarious instigation. Psychological Review, 1962, 69, 450-466.

CRAIG, K., \& LOWERY, J. Heart rate components of conditioned vicarious autonomic response. Journal of Personality \& Social Psychology, 1969, 11, 381-387.

LAZARUS, R., SPIESMAN, J., MORDKOFF, A., \& DAVISON, L. A laboratory study of psychological stress produced by a motion picture film. Psychological Monographs, 1962, 76.

SCHACHTER, S., \& SINGER, S. Cognitive, social, and physiological determinants of emotional state. Psychological Review, 1962 69, 379-399.

VALINS, S. Cognitive effects of false heart-rate feedback. Journal of Personality \& Social Psychology, 1966, 4, 400-408.

WOOD, D., \& OBRIST, P. Effects of controlled and uncontrolled respiration on the conditioned heart rate response in humans. Joumal of Experimental Psychology, 1964, $68,221-229$.

1. The author wishes to express her indebtedness to Dr. Robert B. Zajonc for his guidance and support. The author would also like to thank Michael Hayes who acted as stooge and provided assistance in collection of the data.

\section{Uverlearning of paired associates as a function of test and reinforced trials}

$T$ trials arrest the forgetting that would normally occur between $\mathrm{R}$ trials separated by the same interval and potentiate the conditioning effect of subsequent reinforcements.

Subjective reports from Ss in experiments on mnemonics and explicit mediation (e.g., Delin, 1968, 1969a,b) suggested the possibility that, when material was highly meaningful and presentation times were long, $T$ trials might carry out a more active role in learning. Ss spontaneously reported that they used explicit mediators to get the material "into their heads," and that once this was done the learning was consolidated by outputting the material. Some Ss further reported that once the explicit mediator was constructed, subsequent presentations of the response item were treated, not as new information, but simply as confirmation of the previous learning, and that once they were sure they knew the material they hardly bothered to look at the memory drum.

These reports are consistent with the findings of Olton (1966) and Delin (1969) 